\title{
Um plano educacional para um novo tempo: Anísio Teixeira e as escolas classe/escola parque de Brasília*1
}

\begin{abstract}
An educational plan for a new era: Anísio Teixeira and the "escolas classe/escola parque" (class schools) of Brasília
\end{abstract}

\section{Edilson de Souza*2}

Palavras-chave Escola Classe/Escola

Parque;

Anísio Teixeira Darcy Ribeiro;

CIEPs.
Resumo: O artigo propõe-se a refletir sobre o programa educacional que se materializou nas Escolas Classe/Escola Parque de Brasília na década de 1960, mediante o Plano de Construções Escolares de Brasília, formulado por Anísio Teixeira, apoiado na produção acadêmica do grupo "Educação Básica Pública do Distrito Federal: Origens de um Projeto Inovador (1956-1964)", que tem em seu acervo a memória dos pioneiros da experiência das Escolas Classe/Escola Parque no Distrito Federal. Nesse sentido, são também consideradas as determinações e os investimentos pessoais e profissionais de Anísio Teixeira, intelectual que assumiu a dimensão prática na produção de ideias, considerando a relação dessas ideias com o mundo. Anísio Teixeira procurou fazer que a criação de Brasília conjecturasse também a execução de um projeto pedagógico que pudesse acompanhar o crescimento de uma nova cidade, necessitando de uma reconfiguração socioeconômica, política e cultural que, para obter êxito, devia ser implantada em um local onde a pólis e seu sistema de ensino estivessem iniciando. Ao recuperar essa discussão, desvelamos os debates relacionados à concepção de educação integral, analisando o projeto educacional de nação a partir da escola pública em seu caráter republicano, visando contribuir, junto às demais pesquisas já realizadas, com a temática da educação integral.

${ }^{* 1}$ Recebido em 02/12/2015. Aceito para publicação em 28/01/2016.

$* * 1$ Doutor pelo ProPED-Uerj, assessor da reitoria da Universidade Federal de Santa Maria (UFSM), e.mail: edilsonsouza111@gmail.com. 
Keywords: Abstract: This article intends to stablish reasoning about the School Class/College

Park;

Anísio Teixeira; Darcy Ribeiro; educational program that took place as the "Escolas Classe/Escola Parque" (Class Schools) of Brasilia in the 60's, using the Scholar Buildings Plan of Brasília, created by Anísio CIEP. Teixeira supported by the contributions of the "Educação Básica Pública do Distrito Federal: Origens de um Projeto Inovador (1956-1964)" group, directed by Eva Wisros Pereira, which has in it's library the memories of the Escolas Classe/Escola Parque (Class Schools) pioneers. In that sense, it was also taken in account the delimitations and the professional and personal investments of Anísio Teixeira, intellectual who produced ideas that were somehow related to the external world. He wanted the creation of Brasilia to be the realization of a teaching project that were able to follow the new capital growth, which included a social, economic, political and cultural reorganization that could only happen at birth on the city and it's educational system begin. By starting this discussion it was inevitable to face the integral education concerns, which made urgent to analyze the republican educational project of the nation, contributing, among the other conducted researches, with a integral education view.

\section{Apresentação}

O debate que proponho tem o sentido de discutir o processo de criação das Escolas Parque/Classe de Brasília, apontando os tensionamentos positivos pelos quais passou a construção desse modelo de escola como possibilidade histórica de avanços no âmbito da educação pública. Remeto-me ao Movimento dos Pioneiros da Escola Nova, que se materializaram nas experiências educacionais de Anísio Teixeira, no Centro Educacional Carneiro Ribeiro na Bahia, mais tarde durante a experiência da formação da cidade de Brasília.

Considerado o principal idealizador das grandes mudanças que marcaram a educação brasileira no século 20, Anísio Espínola Teixeira foi pioneiro na implantação de escolas públicas que refletiam seu objetivo de oferecer educação gratuita para todos. Como teórico da educação, Anísio não se preocupava apenas em defender suas ideias, muitas delas inspiradas na filosofia de John Dewey (1852-1952), de quem foi aluno ao fazer um curso de pósgraduação nos Estados Unidos, mas também em fazê-las realidade.

Anísio Teixeira asceu em 12 de julho de 1900, em Caetité (BA). Diplomou-se em 1922 e em 1924 já era inspetor-geral do Ensino na Bahia. Viajando pela Europa em 1925, observou os sistemas de ensino da Espanha, Bélgica, Itália e França, e com o mesmo objetivo fez duas viagens aos Estados Unidos, entre 1927 e 1929. De volta ao Brasil, foi nomeado diretor de Instrução Pública do Rio de Janeiro, onde criou, entre 1931 e 1935, uma rede municipal de ensino que ia da escola primária à universidade. Perseguido pela ditadura 
Vargas, demitiu-se do cargo em 1936 e regressou à Bahia - onde assumiu a pasta da Educação após o fim do Estado Novo, em 1947, implantando em Salvador as Escola-Parque da Bahia. Sua atuação à frente do Instituto Nacional de Estudos Pedagógicos (Inep) iniciou-se em 1952. Trabalhou com Juscelino Kubitschek na implementação do plano educacional para a nova capital, indicou Darcy Ribeiro para coordenar a criação da UnB e o substituiu como seu reitor entre 1963-1964, no governo de João Goulart. Com o golpe militar, foi obrigado a deixar a UnB e o Inep - que hoje leva seu nome - e foi lecionar em universidades americanas, de onde voltou em 1965. Morreu no Rio de Janeiro, em março de 1971, em condições suspeitas sob a averiguação, hoje, da "comissão da verdade" ${ }^{\prime 2}$.

Anísio Teixeira tentou dar escala aos anseios lançados pelo Manifesto dos Pioneiros da Educação Nova de 1932, fazendo que a criação de Brasília fosse também a execução de um projeto pedagógico que pudesse acompanhar o crescimento de uma nova cidade. Tais anseios, nada pequenos, necessitavam de uma reconfiguração socioeconômica, política e cultural que, para obter êxito, devia ser implantada em um local onde a polis e seu sistema de ensino estivessem iniciando, como fala Sousa Júnior:

Se é dado lembrar, mais uma vez, o Manifesto dos Pioneiros da Educação Nova (1932), vale recuperar a atribuição que confere ao Estado do dever, alto, penoso e grave de promover a educação para desenvolver no povo a consciência de si mesmo e de seus destinos e a força para afirmar-se e realizá-los. Talvez resida aí a extrapolação que não deixou que se confinasse no Plano de Brasília as duas condições funcionais cerebralmente projetadas, a de se constituir como uma moderna urbs, no seu sentido mais pragmático e a de se configurar como uma civitas, bela e monumental. (SOUSA JÚNIOR, 2011, pp. 10$11)$.

A estrutura física de Brasília é composta por grandes quadras arborizadas, sendo reconhecida, para além das fronteiras brasileiras, pelo seu planejamento urbanístico e arquitetônico, como expressão contemporânea da criação técnica e artística do país. Anísio acreditava que o novo Distrito Federal se apresentava como cenário propício para a criação de uma nova escola pública e de um novo sistema educacional, que se constituísse de fato enquanto polis.

Foi com o objetivo de oferecer um modelo para esse tipo de escola primária que se projetaram, na Bahia, os Centros de Educação Primária, de que o Centro Carneiro Ribeiro, em Salvador, constituiu a primeira demonstração (TEIXEIRA, 1962, p. 25).

Segundo Pereira e Rocha (2011, p. 32), tudo se constituía em um cenário favorável e as condições eram propícias para a implantação de um "sistema de educação modular". Na nova capital havia disponibilidade plena de espaços

$2 \mathrm{O}$ arquivo pessoal de Anísio Teixeira encontra-se depositado no Centro de Pesquisa e Documentação de História Contemporânea do Brasil (CPDOC) da FGV. Ver, também, Folha de S. Paulo (28/8/77); LEVINE, R. Vargas; OLIVEIRA, C. Biografias; SOUSA, A. Baianos. 
físicos para a edificação dos complexos conjuntos escolares propostos por Anísio Teixeira.

Em "Estado Atual da Educação" (1963), publicado na Revista Brasileira de Estudos Pedagógicos, Anísio Teixeira afirmava sua convicção de que não bastava o nascimento de uma cidade, mas, junto com essa nova polis, deveria crescer uma proposta educacional que acompanhasse as necessidades educacionais, tendo em vista as condições que faziam a educação passar por um processo de deterioração após as reformas de 1920, que o autor analisa seguindo uma linha histórica entre 1914 e 1960.

\section{De Salvador à nova capital: uma escola republicana}

Somente após a Segunda Guerra Mundial é que se inicia de fato o processo de industrialização no país, com reflexos manifestos no sistema de ensino. A reforma de Sampaio Dora, no Estado de São Paulo, dá início ao movimento chamado de democratização do ensino primário, em que o estado assumiria a proposta de reduzir em dois anos a escolarização, definida em três anos para a zona rural e quatro para a zona urbana. Propostas semelhantes seguem a esta em diferentes Estados da federação: a de José Augusto, no Rio Grande do Norte, em 1924; a de Anísio Teixeira, na Bahia, em 1925; a de Francisco Campos e de Mario Casassanta, em Minas, em 1927; a de Fernando Azevedo, no Distrito Federal (Rio de Janeiro), em 1928; e a de Carneiro Leão, em Pernambuco, em 1929, todas elas buscando a universalização das primeiras letras.

Alarmados pelo índice de mais de 50\% da população entre 7 e 12 anos fora da escola no Brasil, alguns educadores buscavam uma escola primária com a duração letiva de dois anos, gratuita e obrigatória para todos, tendo como objetivo garantir a universalização das primeiras letras, isto é, a alfabetização de todas as crianças em idade escolar. A reforma, no entanto, resultou em "um tipo de escola primária, aligeirada e simples" e "recebeu muitas críticas" (SAVIANI, 2007, p. 175).

O que já se havia conseguido na França com o advento da Revolução, no Brasil do século XX ainda não era alcançado devido ao desinteresse de sua elite, apoiada pela Igreja Católica, mesmo tendo o aporte do Manifesto dos Pioneiros pela Educação Nova (1932). De fato, o que se objetivava na escola pública brasileira era suprir os interesses do trabalho urbano. Pobres, negros e marginalizados estavam fora, porém, do público atingido.

A redução do ensino primário de 4 para 2 anos foi o "calcanhar de Aquiles" da reforma. Posteriormente justificada como uma necessidade circunstancial de reorganização das escolas e classes, sua implementação prática estabeleceu a ideia de que 2 anos de escolarização eram suficientes para a massa da população, na medida em que eram suficientes para a alfabetização. A racionalização administrativa tentava impor-se às determinações de ordem política, histórica e ideológica mas, na prática, era reinterpretada por estas. (CAVALIERE, 2003, p. 37)

Anísio Teixeira, em contrapartida, acreditava que um aumento no tempo escolar resultaria em melhor qualidade nas práticas educativas, no momento em que a ampliação do tempo pudesse ser uniformizada e pudesse atender 
positivamente às necessidades de uma sociedade em construção. Para Cavaliere, essa ampliação continha diferentes enfoques:

A ampliação do tempo diário de escola pode ser entendida e justificada de diferentes formas: (a) ampliação do tempo como forma de se alcançar melhores resultados da ação escolar sobre os indivíduos, devido à maior exposição desses às práticas e rotinas escolares; (b) ampliação do tempo como adequação da escola às novas condições da vida urbana, das famílias e particularmente da mulher; (c) ampliação do tempo como parte integrante da mudança na própria concepção de educação escolar, isto é, no papel da escola na vida e na formação dos indivíduos. (CAVALIERE, 2007, p.11)

Por meio do Centro Carneiro Ribeiro/Escola Parque, Anísio assinalou para a nação seu projeto de educação, que daria acesso à população desatendida, oportunidade negada durante séculos. Anísio Teixeira I para Brasília a experiência de Salvador, o princípio primordial do Manifesto dos Pioneiros da Educação Nova, a relação entre educação e democracia, evidenciando a imbricação entre educação pública e ação estatal, reafirmando o direito de todos ao ensino público e, por outro lado, a responsabilidade do Estado com a garantia de acesso à educação escolar.

O processo de construção de Brasília faz parte de um movimento pós-II Guerra Mundial, inserido no espaço da democracia liberal e do nacional desenvolvimentismo. Em 1960 foi inaugurada a nova capital, que só seria verdadeiramente a sede das decisões nacionais após 1964, em plena ditadura. O governo autoritário inicia o chamado milagre econômico e os anos de chumbo também foram acompanhados de aumento da concentração de renda e da pobreza. Brasília teve início oficial a partir de 21 de abril de 1960.

O projeto de Kubitscheck levou adiante um plano de metas conhecido pelo slogan 50 anos em cinco, simbolizado pela construção da nova capital no interior do Brasil, procurando desenvolver no país as condições necessárias ao crescimento, por meio da industrialização e desenvolvimento geral nacional.

Brasília simbolizava, em 1960, a materialização da ruptura com o passado e o nascimento de um novo país, manifestação "utópica"”, potencializando um mundo onde seriam melhores as condições de vida e as relações humanas. Quando se fala em utopia como "ideal de vida humana", não há explicitamente uma preocupação sobre se esse ideal é possível de ser concretizado ou não, mas uma crença em suas potencialidades, colocando pronto para o futuro, para tornar-se grandioso.

A nova capital constituiu-se como uma das "metas"4 do governo de Juscelino Kubitschek, e tornou-se o grande palco onde a educação seria

\footnotetext{
3 "A educação crítica é a 'futuridade' revolucionária. Ela é profética e, como tal, portadora de esperança - e corresponde à natureza histórica do homem. Ela afirma que os homens são seres que se superam. Que vão para a frente e olham para o futuro, seres para os quais a imobilidade representa uma ameaça fatal. Para os quais ver o passado não deve ser mais que um meio para compreender claramente quem são e o que são, a fim de construir o futuro com mais sabedoria. Ela se identifica, portanto, com o movimento que compromete os homens como seres conscientes de sua limitação, movimento que é histórico e que tem o seu ponto de partida. O seu sujeito. O seu objetivo" (FREIRE, 1979, pp. 81-82).

4 O Programa de Metas tinha como objetivo aumentar e gerar novos investimentos em
} 
elemento fundamental no desenvolvimento social, segundo Pereira e Rocha (2011). A partir do momento em que se instalam as primeiras famílias de trabalhadores e funcionários no Planalto Central, a preocupação com a educação aumenta, por se tornar um lugar de grande fluxo migratório, criando uma demanda emergencial para o poder público.

os operários que vieram construir Brasília tinham exigências relativamente pequenas quanto à educação. Grande número deles era de analfabetos, o que se verificou quando do enquadramento dos trabalhadores da NOVACAP. A grande maioria não tinha aspirações maiores de educação para si ou para seus familiares. (...). Já os funcionários transferidos exigiam educação de melhor qualidade para seus filhos. Não Ihes era suficiente a alfabetização e o curso primário. Era-Ihes necessário o ensino médio e de boa qualidade. (apud DF 2001, p. 67).

A Lei no 2.874, de 19 de setembro de 1956, versava sobre a delimitação do Distrito Federal e sobre a constituição da NOVACAP. Esta Lei definia, dentre as múltiplas atribuições da NOVACAP, a organização de um sistema educacional. Para tanto, desde o início da construção de Brasília, foi criado o Departamento de Educação e Difusão Cultural.

Em 1957 chegaram a Brasília as primeiras famílias, o que demandou a composição de um corpo docente em caráter de urgência. As primeiras professoras foram selecionadas entre esposas e filhas de funcionários, portadoras de diplomas de normalista expedidos por escola oficial, como afirma a professora Anísia Santos da Rocha Cravo5:

Meu esposo veio em março e, um mês e pouco depois - em abril -, eu vim com as crianças. Ele veio trabalhar na Construtora Nacional, que construiu o Congresso. E eu vim apenas acompanhando. Porém, um mês depois de aqui chegar eu já era professora em Brasília, porque a Construtora Nacional resolveu abrir uma escolinha, já que havia muitas crianças, filhos dos seus funcionários. Como nós chamávamos... uma escolinha. Era uma escola para cerca de quinze crianças, com $1^{a}, 2^{a}$ e $3^{a}$ séries. E eu lecionava para esses meninos. (CRAVO, 2001, s/p)

atividades de produção, por meio do processo de acumulação capitalista. Em seus discursos de campanha, Juscelino justifica que esse processo levaria a uma vida melhor para todos, porque garantiria emprego e renda, promovendo o desenvolvimento através da produção em massa. Tendo como estratégia a industrialização, ao estado caberiam as condições de demanda, a infraestrutura necessária à produção e à regulação social. O Programa incorporava 31 metas, divididas em seis grupos: energia, transporte, alimentação, indústrias de base, educação e a construção de Brasília - a meta síntese.

${ }^{5}$ Mostro um pouco do acervo do Projeto de Pesquisa "Educação básica pública no Distrito Federal (1956-1964): origens de um projeto inovador"; tomamos a liberdade de usar algumas entrevistas como fontes, que não foram realizadas em um mesmo espaço de tempo, transcorrendo suas realizações no período de 1990 a 2007, e não foram realizadas pelos mesmos entrevistadores. No entanto, entendendo que os perfis dos entrevistados são quase os mesmos, professores da educação básica, especificamente do ensino primário (fundamental), que atuaram na rede pública de ensino do Distrito Federal, no período de 1957 a 1960, é possível sua retomada para fins desta investigação. 
Também foram selecionadas algumas professoras de Goiás, devido à proximidade com a nova Capital, que tivessem boa qualificação e experiência anterior. Entre os professores contratados pela Companhia Urbanizadora da Nova Capital do Brasil, a NOVACAP6, havia também os que vieram de outros Estados, como Minas Gerais, o que contribuiu para agregar diferentes influências didático-pedagógicas.

A construção da nova capital do Brasil constituía-se em uma das metas da política nacional-desenvolvimentista implementada pelo governo Juscelino Kubitschek. Brasília seria um ponto de germinação para o interior, visando à integração entre centros urbanos e regiões agropecuárias, por meio de um complexo rodoviário (PEREIRA e ROCHA 2011, p. 28).

A professora Amábile Andrade Gomes relata sua pioneiríssima atuação na educação brasiliense, uma vez que sua primeira turma tinha como sala de aula a sala de reuniões da diretoria da NOVACAP, antes ainda da inauguração da primeira escola - grupo escolar Júlia Kubitschek - em 1957. Depois integrou o corpo docente dessa primeira escola oficial de Brasília, de onde foi transferida para a escola-classe da quadra 308 Sul.

[...] a ideia do governo não era trazer as famílias, era trazer só os operários. Mas eles não conseguiram segurar as famílias, as famílias foram [...], e os padres começaram a pressionar o Dr. Sayão, que era o que ficava, o diretor que ficava lá. Ele era diretor administrativo, diretor executivo [...], a família dele foi. E ele então perguntou para o meu marido: "A sua esposa é professora?" Meu marido respondeu: "É". E ele: "Então vamos te empurrar [...]". E foi assim. As resoluções do Dr. Sayão eram todas muito efetivas. Ele resolvia na hora, mandava despacho para [...], ele me ajudou a montar essa escola [...]. No dia em que havia reunião, os meninos, os alunos, saíam. [risos] A gente dispensava. E todo mundo se reunia (GOMES, 2002, s/p).

Segundo a professora, nesse período havia a sua turma, na sala da NOVACAP, e uma única outra escola, no Núcleo Bandeirante, "o colégio Batista, escola Batista, no Núcleo Bandeirante: "Existe até uma foto com uma professora dando aula embaixo da árvore", conta ela.

As duas primeiras escolas foram de iniciativa privada, localizadas no Núcleo Bandeirante. Somente em 18 de outubro de 1957 é inaugurado o Grupo

\footnotetext{
${ }^{6}$ Companhia Urbanizadora da Nova Capital. Durante as primeiras obras, de 1956 a 1960, a NOVACAP foi responsável por educação, cultura e lazer; saúde, segurança e transporte; finanças, telecomunicações e habitação; abastecimento de água e luz. Os primeiros candangos fizeram aparecer as primeiras obras de arte, criadas pelo então chefe do Departamento de Urbanismo e Arquitetura (DUA/NOVACAP), Oscar Niemeyer, e as primeiras vias do traçado original da cidade, concebido pelo urbanista Lúcio Costa. A NOVACAP construiu, até 1960, os principais edifícios públicos da cidade: Congresso Nacional, Catedral e Teatro Nacional; palácios, ministérios e rodoviária; Jardim Zoológico, Torre de TV e usinas hidrelétricas e termelétricas. Construiu, também, os tribunais, o aeroporto internacional Juscelino Kubitschek e o Hotel Brasília Palace, bem como residências, clubes, igrejas, hospitais, escolas, entre outros. A Companhia executou, ainda, todos os serviços de infraestrutura, como redes de água potável, coletoras de esgotos sanitários, galerias de águas pluviais, redes telefônicas e de energia elétrica. Disponível em: http://www.novacap.df.gov.br/ Acesso em set. 2015.
} 
Escolar 1 (GE-1), depois chamado de Escola Júlia Kubitschek. O prédio escolar projetado por Niemeyer localizava-se na atual Candangolândia. A escola funcionava em dois turnos, mas as crianças permaneciam três horas extras em atividades sociais. O primeiro turno era das 7:30 às $15 \mathrm{~h}$, e o segundo tinha início às $9 \mathrm{~h}$, terminando às 17:30h. As crianças faziam três refeições na escola.

À proporção que a cidade crescia, que os acampamentos se multiplicavam, novas escolas iam sendo construídas, de tal forma que não havia, à época da construção de Brasília, uma só criança sem escola. (SILVA, 1985, p. 241).

O Plano de Construções Escolares para Brasília obedeceu ao propósito de abrir oportunidade para a Capital Federal e oferecer à Nação um conjunto de escolas que pudessem constituir exemplo e demonstração para o sistema educacional do País. (TEIXEIRA, 1961, p. 195)

Em 22 de dezembro de 1959, foi instituída a Comissão de Administração do Sistema Educacional de Brasília (CASEB), pelo Decreto no 47.4727, com seis diretores do Ministério da Educação - MEC, e um representante da NOVACAP, contando com recursos da União para construir e manter as escolas, no ano de 1960. Portanto, a Comissão seria encarregada de implementar o Plano de Construções Escolares de Brasília, elaborado por Anísio Teixeira. Também participou como membro de seu colegiado deliberativo, assumindo a responsabilidade pela elaboração do documento que ficou conhecido como Plano de Construções Escolares de Brasília8, publicado em 1961, na Revista Brasileira de Estudos Pedagógicos (PEREIRA; ROCHA, 2011).

É certo que iríamos enfrentar - como, de fato, ocorreu mais tarde - uma luta titânica. Sabíamos que forças poderosas se ergueriam contra as fórmulas progressistas. Pressentíamos que os rotineiros, os homens de alma velha, os eternos inimigos do progresso lançariam mão de todos os recursos para destruírem tais ideias rejuvenescedoras. Lançamo-nos, todavia, à luta. Para a realização de uma grande obra é necessário recrutar uma equipe capaz. E quem seria mais indicado que Anísio Teixeira para fornecer a chave mestra e indicar as linhas básicas do plano? Foi a ele que nos dirigimos. Recebeu-nos de braços abertos. Fixou as normas gerais e pôs à nossa disposição o competente Paulo de Almeida Campos, que deu tudo de si, que se integrou à missão, que representou à altura a figura do grande educador. Além de Paulo Campos, convocamos também, para tomar parte no trabalho de organização do Plano e seleção e orientação das professoras, a técnica de educação Nair Durão Barbosa Prata (SILVA, 1999, p. 227).

Anísio Teixeira deu a definição filosófica do "Plano de Construções Escolares de Brasília", a ser implementado após a inauguração da nova Capital. Silva (1985) detalha os objetivos que nortearam a formulação do plano educacional, entre os quais destacam-se:

a) distribuir equitativa e equidistantemente as escolas no Plano-Piloto e Cidades-Satélites, de modo que a criança percorresse o menor trajeto possível

7 Ver Decreto Presidencial n. 47.472, de 22 de novembro de 1959.

8 Ver: Anísio Teixeira. Plano de Construções Escolares de Brasília. Revista Brasileira de Estudos Pedagógicos, n. 81, vol. 35, jan./mar. 1961, pp. 195-199. 
para atingir a escola, sem interferência do tráfego de veículos, para a comodidade e tranquilidade de pais e alunos;

b) concentrar as crianças de todas as classes sociais na mesma escola (democratização);

c) possibilitar o ensino a todas as crianças e adolescentes;

d) romper com a rotina do sistema educacional brasileiro pela elaboração de um plano novo, que proporcionasse à criança e ao adolescente uma educação integral;

e) reunir em um só centro todos os cursos de grau médio, permitindo-se maior sociabilidade aos jovens da mesma idade que, embora frequentando classes diferentes, tivessem em comum atividades na biblioteca, na piscina, nos campos de esportes, nos grêmios, no refeitório etc.

A organização e os pressupostos da escola, que se defendia ser modelo para o país, indicavam a permanência em tempo integral em todas as etapas e/ou níveis da educação, inclusive para os professores, de modo que a educação pudesse alcançar, de forma integral e integradora, os aspectos educacionais, sociais e cívicos que comporiam a plena formação do estudante/cidadão.

Portanto, o ensino a que se propunha o Plano, seguia algumas diretrizes:

a) elaboração de um original sistema de ensino, em que fossem eliminados do currículo temas inadequados e introduzidos os recursos da televisão, do rádio e do cinema;

b) dia letivo de tempo integral;

c) escola como centro de preparação para a vida moderna, firmando atitudes, cultivando aspirações;

d) escola oferecendo oportunidades à criança e ao adolescente para viverem uma civilização técnica e industrial, sempre em mutação;

e) divisão da escola em dois setores: 1. o da instrução propriamente dita, com o trabalho tradicional da classe; 2. o da educação, com as atividades socializantes, recreativas e artísticas (música, teatro, dança, pintura, cinema, exposições, grêmios, educação física), trabalho manual e artes industriais (costura, bordado, encadernação, tapeçaria, cestaria, cartonagem, tecelagem, cerâmica, trabalhos em madeira e metal etc.);

f) correção, enfim, do desajuste que existe entre o nosso progresso material e o atraso educacional.

Ao mesmo tempo, o plano educacional acompanhava as características inovadoras da metrópole, o que foi expresso no documento intitulado "Plano de Construções Escolares de Brasília" (TEIXEIRA, 1961). Como propósito, assinalava "oferecer à Nação um conjunto de escolas que pudessem constituirse exemplo e demonstração para o sistema educacional do país", como conta Teixeira (1961, p. 195).

Na elaboração da proposta, Anísio Teixeira retoma as orientações pelas quais, desde os anos de 1920-1930, pautara as suas iniciativas para transformar a escola, com base nos princípios da filosofia pragmatista, de forma coerente com a sua visão de mundo. Para ele, a designação "escola nova" era meramente estratégica e servia apenas para delimitar as fronteiras dos campos adversos, em campanha para transformar instituição escolar. (PEREIRA, 2011, p. 50) 
Ao traçar um panorama do que seria o Sistema Educacional de Brasília, Anísio Teixeira aponta os caminhos da educação como direito fundamental, desconstruindo a ideia de privilégio das elites e reafirmando a educação pública, radicalmente democrática. O Plano Educacional de Brasília traz consigo o ideal escolanovista, interpretado e assimilado por Anísio para a "reconstrução das escolas".

A ideia de "educação comum", da escola pública americana ou da école unique francesa, não era nada disto. Não se cogitava de dar ao pobre a educação conveniente ao rico, mas, antes, de dar ao rico a educação conveniente ao pobre, pois a nova sociedade democrática não deveria distinguir, entre os indivíduos, os que precisavam dos que não precisavam trabalhar, mas a todos queria educar para o trabalho, distribuindo-os pelas ocupações, conforme o mérito de cada um e não segundo a sua posição social ou riqueza. [...] Não se tratava de generalizar a educação para os "privilégios", mas de acabar com tais "privilégios", em sua sociedade hierarquizada nas ocupações, mas desierarquizada socialmente (TEIXEIRA, 1977, p. 29)

As escolas "anisianas" propunham o rompimento com o passado e a constituição de um novo pensamento pedagógico, em parte inspirado nas ideias de John Dewey. O projeto de Anísio Teixeira procurava formar os cérebros criativos e autônomos que governariam o País do futuro.

Este pensamento inspirou a formulação do "Plano de Construções Escolares de Brasília" (TEIXEIRA, 1961), de modo que as condições arquitetônicas atendessem também às necessidades pedagógicas e que os prédios de educação "elementar" e "secundária" contemplassem amplos espaços de integração de salas de aula, de atividades variadas, educação física, biblioteca, organizados em pavilhões.

Já não se trata de escolas e salas de aula, mas de todo um conjunto de locais, em que as crianças se distribuem, entregues às atividades de 'estudo', de 'trabalho', de 'recreação', de 'reunião', de 'administração', de 'decisão' e de vida e de convívio no mais amplo sentido desse termo. A arquitetura escolar deve assim combinar aspectos da 'escola tradicional' com os da 'oficina', do 'clube' de esportes e de recreio, da 'casa', do 'comércio', do 'restaurante', do 'teatro', compreendendo, talvez, o programa mais complexo e mais diversificado de todas as arquiteturas especiais (TEIXEIRA, 1961, p. 197).

Dessa maneira, Anísio apresentou em Brasília um sistema de educação que acompanhava todo o processo de desenvolvimento da cidade, e que a partir "do ponto de vista das construções, constitui um desafio aos arquitetos de Brasília, oferecendo-lhes a oportunidade para a concepção de novos e complexos conjuntos escolares" (TEIXEIRA, 1961, pp. 195-196).

O sistema de ensino era composto pelas seguintes instituições escolares: a) Centros de Educação Elementar, integrados por Jardins de Infância, EscolasClasse e Escolas-Parque; b) Centros de Educação Média, destinados à Escola Secundária Compreensiva e ao Parque de Educação Média; c) Universidade de Brasília, composta de Institutos, Faculdades e demais dependências destinadas à administração, biblioteca, campos de recreação e desportos (TEIXEIRA, 1961, pp. 195-196).

Quando da iniciação para o trabalho, visava a formação a partir dos 7 anos (oficinas de artes industriais), entendendo Anísio Teixeira as implicações 
da ciência moderna, do desenvolvimento industrial e da preparação para o trabalho na formação do homem comum para um mundo onde "tudo está a mudar e a se transformar" (TEIXEIRA, 1930, p. 9). Portanto, a ciência e a tecnologia deveriam ser inseridas na proposta e no sistema.

Lado a lado com o progresso científico, a sociedade moderna deveria dispor de uma organização social em que todos os homens tivessem igualdade de oportunidades e, assim, pudessem se desenvolver segundo suas aptidões individuais e viver uma vida digna, de bem-estar crescente, fundada no trabalho e em uma estrutura social justa (ROCHA, ANTONIAZZI, 2011, p. 83).

Buscando a superação do dualismo vigente entre o saber e o agir, defendia-se a introdução do método científico na educação, "dar aos seus métodos, processos e materiais, a segurança inteligente, a eficácia controlada e a capacidade relativamente menos complexa" (TEIXEIRA, 1955, p. 5). De modo a suplantar, inclusive, o individualismo da formação moderna, intensificada do processo tecnológico, criando-se a "cultura tecnológica" que representa, "mais do que tudo, o reino dos meios em contraposição ao reino dos fins e valores fundamentais da vida humana" (TEIXEIRA, 1971, p.19).

A inserção do trabalho na escola trazia a compreensão da habilidade, da criação, de conhecer e descobrir usos para as ferramentas e não apenas como atividade com fins econômicos. Trabalho e brinquedo compõem o mundo criativo da criança e contribuem para seu desenvolvimento intelectual. Impedir que a criança se expresse por meio do trabalho é frear o seu desenvolvimento criativo, quando ela já está apta para fazê-lo (ROCHA; ANTONIAZZI, 2011, p. 96).

A escola para todos era espaço e tempo integradores de uma formação baseada na ação e na participação coletiva e democrática, completadas por vivências que, combinadas, promoveriam a educação integral numa sociedade em transformação.

Se na escola-classe predomina o sentido preparatório da escola, na escola-parque, nome que conferiu ao conjunto de edifícios de atividades de trabalho, sociais, de educação física e de arte, predomina o sentido de atividade completa, com suas fases de preparo e de consumação, devendo o aluno exercer, em sua totalidade, o senso de responsabilidade e de ação prática, seja no trabalho, que não é um exercício, mas a fatura de algo completo e de valor utilitário, seja nos jogos e na recreação, seja nas atividades sociais, seja no teatro ou nas salas de música e dança, seja na biblioteca, que não é só de estudo, mas de leitura e de fruição de bens do espírito (TEIXEIRA, 1967, p.130).

Independentemente da classe social, sem a velha dicotomia entre formação geral e formação especial, entre formação para o trabalho e formação para o lazer, que tem caracterizado a educação brasileira ao longo do tempo, Anísio Teixeira repensava a instituição escolar em seus fundamentos, alterando seus objetivos, a sua organização e os modos de funcionamento, transformando, portanto, um sistema de educação discriminatória, de privilégios, em um sistema de educação democrático, igualitário (PEREIRA, 2011). 


\section{Considerações finais}

Inspirado nas mudanças demandadas pelos anseios provocados pelo Movimento de 1932, que lançou o conhecido Manifesto dos Pioneiros da Escola Nova, Anísio Teixeira rogou pela qualidade da escola pública, inserindo a discussão sobre educação integral. O educador baiano fazia uma forte crítica à escola tradicional, considerando-a inadequada à formação dos cidadãos para uma nova sociedade, excludente e incapaz de dar conta da demanda social dos trabalhadores. Anísio propugnava a emancipação da nação e do homem brasileiro como meio de superar o subdesenvolvimento a partir da estrutura de um novo sistema de educação: único, democrático, acessível a todos (PEREIRA, 2011). Na ênfase ao ensino primário, nem por isso Anísio Teixeira se limitava a este nível, mas pensava sua continuidade: "o plano consiste em cada nível de ensino, desde o primário até o superior ou terciário" (1961, p. 195).

Em seu plano educacional para a nova capital, os alunos frequentavam diariamente a "escola-parque" e a "escola-classe", em turnos diferentes, passando quatro horas nas classes de educação intelectual e outras quatro nas atividades da escola-parque, com intervalo de almoço. Nessas condições, a educação elementar associa o ensino propriamente intencional, da sala de aula, com a autoeducação, resultante de atividades em que os alunos teriam uma participação com responsabilidade. Em consequência, o horário escolar se estendia por oito horas, dividido entre as atividades de estudo e as de trabalho, de arte e de convivência social (TEIXEIRA, 1961, p. 197).

A democratização do ensino almejada por Anísio Teixeira se dava, entretanto, em meio a uma sociedade estratificada, marcada pelo subdesenvolvimento, ainda que as escolas Classe/Parque se beneficiassem da rara possibilidade histórica de se constituir concomitantemente à construção de uma capital nacional, de modo que se investia numa escola renovada a promover a igualdade de oportunidades, essência do regime democrático.

O Golpe de 1964 impôs a interrupção deste trabalho. O tempo, em sua dimensão histórico-pedagógica, contudo, assinala que a força de um acontecimento tem a peculiaridade exata do momento em que está acontecendo, e jamais pode ser reconstruído ou modicado por anseios ou desejos pessoais fora do tempo do acontecimento. Cabe perguntar, agora, acerca de seu legado para os novos tempos que se apresentam no correr da história de maneira que o conhecimento das experiências havidas pode funcionar não como uma idealização do passado, mas como condição para se realizar mais lucidamente as escolhas do presente. Assim, é verdade que a oferta de diferentes regimes de jornada escolar, sejam eles parcial, integral, ampliado, dependerá das demandas de cada contexto particular.

Recuperar, contudo, o prejuízo histórico que levou milhões de crianças e jovens a perderem seu direito à escola com o mínimo quatro horas diárias, ao longo de sua formação, tornou-se o desafio da vida de Anísio Teixeira. Este texto procurou lembrar isso e, quiçá, manter tal desafio na agenda pública, sem esquecer sua proposta pedagógica muito peculiar e a visão que lhe dava sustentação: a construção de uma escola efetivamente republicana. 


\section{Referências}

CAVALIERE, A. 2002. Educação integral: uma nova identidade para a escola brasileira? In: Educação e Sociedade, Campinas, v. 23, n. 81.

. Entre o pioneirismo e o impasse: a reforma de 1920. Educação e Pesquisa, São Paulo, v. 29, n. 1, p. 27-44, jan./jun. 2003.

FREIRE, P. Conscientização, Teoria e prática da libertação. São Paulo. Cortez \& Moraes. 1979.

KUBITSCHEK, Juscelino. Porque construí Brasília. Brasília: Senado Federal, Conselho Editorial, 2000.

NUNES, C. Anísio Teixeira entre nós: A defesa da educação como direito de todos. Educação \& Sociedade, v. 73, pp. 9-40, 2000.

História da Educação: espaço de desejo. Em Aberto, Brasília, v. 9, n. 47, pp. 37-45, 1990.

PEREIRA, E. W.; CARVALHO, P. M. Resistência, contradições e impasses na concretização do plano de Anísio Teixeira. In: PEREIRA, E. W.; MAGALHAES, F. H.; ROCHA, L. M. F.; COUTINHO, L.; HENRIQUES, C. M. N.; MENDONÇA, A. W.; MORAES, R. A. (Org.). Nas asas de Brasília: memórias de uma utopia educativa (1956-1964). 1 ed. Brasília: Editora da Universidade de Brasília, 2011.

PEREIRA, E. W.; ROCHA, L. M. F. Anísio Teixeira e o plano educacional de Brasília. In: PEREIRA, E. W.; MAGALHAES, F. H.; ROCHA, L. M. F.; COUTINHO, L.; HENRIQUES, C. M. N.; MENDONÇA, A. W.; MORAES, R. A. (Org.). Nas asas de Brasília: memórias de uma utopia educativa (19561964). 1 ed. Brasília: Editora da Universidade de Brasília, 2011.

Escola Normal de Brasília: a formação de professores na perspectiva da modernidade. In: ARAUJO J. C. S.; FREITAS, A. G. B.; LOPES, A. P. C. (Orgs). As escolas normais do Brasil: do império a república. Campinas: Alínea: 2008. pp. 355-370.

; ROCHA, L. M. da F. Anísio Teixeira e o plano de educação de Brasília. In: Por uma política de formação do magistério nacional: o INEP/MEC dos anos 1950/1960, 2008. pp. 241-260.

ROCHA, L. M. F.; ANTONIAZZI, M. R. F. Anísio Teixeira: educação integral e formação para o trabalho. In: PEREIRA, E. W.; MAGALHAES, F. H.; ROCHA, L. M. F.; COUTINHO, L.; HENRIQUES, C. M. N.; MENDONÇA, A. W.; MORAES, R. A. (Org.). Nas asas de Brasília: memórias de uma utopia educativa (1956-1964). 1 ed. Brasília: Editora da Universidade de Brasília, 2011.

SAVIANI, Dermeval. História das idéias pedagógicas no Brasil. Campinas: Autores Associados, 2007.

SILVA, Ernesto. História de Brasília: um sonho, uma esperança, uma realidade. Brasília: Linha Gráfica Ed., 1999.

SOUSA JUNIOR, J. G. Apresentação. In: PEREIRA, E. W.; MAGALHAES, F. H.; ROCHA, L. M. F.; COUTINHO, L.; HENRIQUES, C. M. N.; MENDONÇA, A. W.; MORAES, R. A. (Org.). Nas asas de Brasília: memórias de uma utopia educativa (1956-1964). 1 ed. Brasília: Universidade de Brasília, 2011.

TEIXEIRA, A. A crise educacional brasileira. Revista Brasileira de Estudos Pedagógicos. Rio de Janeiro, v. 19, n. 50, abr./jun. 1953. pp. 20-43. 
. A educação comum do homem de hoje. In: Educação no Brasil. 2 ed. Atualidades pedagógicas, v. 132. São Paulo: Nacional; Brasília, DF: INL/MEC, 1976. pp. 362-366.

. A escola brasileira e a estabilidade social. In: TEIXEIRA, A. Educação no Brasil. São Paulo: Nacional; INL - MEC. 1976.

- A Escola Parque da Bahia. Revista Brasileira de Estudos Pedagógicos. Rio de Janeiro, v. 47, n. 106, pp. 246-253, abr./jun. 1967.

A escola pública universal e gratuita. Revista Brasileira de Estudos Pedagógicos. Rio de Janeiro, v. 26, n. 64, pp. 3-27, out./dez. 1956.

A Pedagogia de Dewey: esboço da teoria de educação de John Dewey. In: DEWEY, John. Vida e educação. 10 ed. São Paulo: Melhoramentos, 1978.

- Centro Educacional Carneiro Ribeiro. Revista Brasileira de Estudos Pedagógicos. Rio de Janeiro, v. 31, n. 73, pp. 78-84, jan./mar. 1959. . Ciência e humanismo. Revista Brasileira de Estudos Pedagógicos. Rio de Janeiro, v.24, n.60, 1955. pp.30-44.

. Educação é um direito. 3 ed. Rio de Janeiro: UFRJ, 2004.

. Educação não é privilégio. 4 ed. São Paulo: Nacional, 1977.

. Educação no Brasil. 2 ed. São Paulo: Nacional; Brasília: INEP/MEC, 1976.

Estado atual da educação. Revista Brasileira de Estudos Pedagógicos. Rio de Janeiro, v. 39, n. 89, pp. 8-16, jan./mar, 1963.

. O problema de formação do magistério. Revista Brasileira de Estudos Pedagógicos. Brasília, v. 46, n. 104, pp. 278-287, out./dez. 1966.

. Padrões brasileiros de educação [escolar] e cultura. Revista Brasileira

de Estudos Pedagógicos. Rio de Janeiro, v.22, n.55, jul./set. 1954, pp.322.

Pequena introdução à filosofia da educação. Rio de Janeiro: DP\&A, 2000.

Porque "Escola Nova". Boletim da Associação Bahiana de Educação. Salvador, $\quad$ n.1, 1930. http://www.bvanisioteixeira.ufba.br/artigos/nova.htm pp.2-30.

- Plano de Construções Escolares de Brasília. Revista Brasileira de Estudos Pedagógicos. Rio de Janeiro, v. 35, n. 81, pp. 195-199, jan./mar. 1961.

- Uma experiência de educação primária integral no Brasil. Revista Brasileira de Estudos Pedagógicos. Rio de Janeiro, v. 38, n. 87, pp. 21-33, jul./ set. 1962.

VIÑAO FRAGO, Antonio e ESCOLANO, Augustin. Currículo, espaço e subjetividade: a arquitetura como programa. Rio de Janeiro: DP\&A, 1998. 